\title{
Sistemas Modernos de Contabilidad
}

\section{Modern Accounting Systems}

Dra. Verónica Juárez Fonseca; Dr. Alfredo Pérez Paredes²;

Dr. Jorge Manuel García Vázquez ${ }^{3}$

\section{Palabras clave:}

Sistemas contables, métodos, contabilidad, estados financieros

Reseña de libro:

Fecha de recepción: $30 / 06 / 2020$

Fecha de aceptación: $10 / 07 / 2020$

Esta publicación se encuentra bajo licencia:

Creative Commons ReconocimientoNoComercialSinObraDerivada 4.0 Internacional

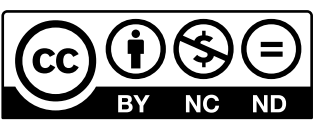

\section{Resumen}

El libro trata de temas relevantes y actuales acerca de los sistemas, métodos y registros contables a partir de la segunda década del siglo XX. Los primeros conocimientos vinculados a la función de la contaduría se ven reflejados en la aportación univoca que el autor consuma con la expresión al castellano, con un estilo particular elocuente y sutil, sin apartarse de los tecnicismos científicos provenientes de otro continente. Este es el primer libro de contabilidad en México, que traduce conceptos y tecnicismos del inglés (Inglaterra y Estados unidos de Norte América) al español sin descuidar las funciones y necesidades empresariales mexicanas.

Esta primera aportación, centra su objetivo en proporcionar los conocimientos al argot contable y la convergencia hacia estudios de casos de empresas reales que iniciaban sus operaciones en México, como intento de resarcir la economía debilitada por las secuelas de la revolución mexicana. Asimismo,

1 Contador Público y Auditor. Dra. En Investigación e Innovación Educativa, ex becaria Conacyt. Investigadora de la Facultad de Administración de la Benemérita Universidad Autónoma de Puebla .México. Correo electrónico: titosfonseca@yahoo.com.mx ORCID: https://orcid.org/0000-0002-0562-1063

2 Administrador de Empresas. Dr. Administración Pública. Investigador tiempo completo de la Facultad de Administración de la Benemérita Universidad Autónoma de Puebla. México. Correo electrónico alfredoperez2001@ hotmail.com ORCID: https://orcid.org/0000-0001-8766-5766

3 Lic. En economía. Doctor en Ciencias Económicas. Investigador-Metodólogo Económico-Financiero del Vicerrector Primero de la Universidad Central "Marta Abreu" de Las Villas. Cuba. Correo electrónico: jmgvazquez@nauta. cu ORCID: https://orcid.org/0000-0001-5394-6930 


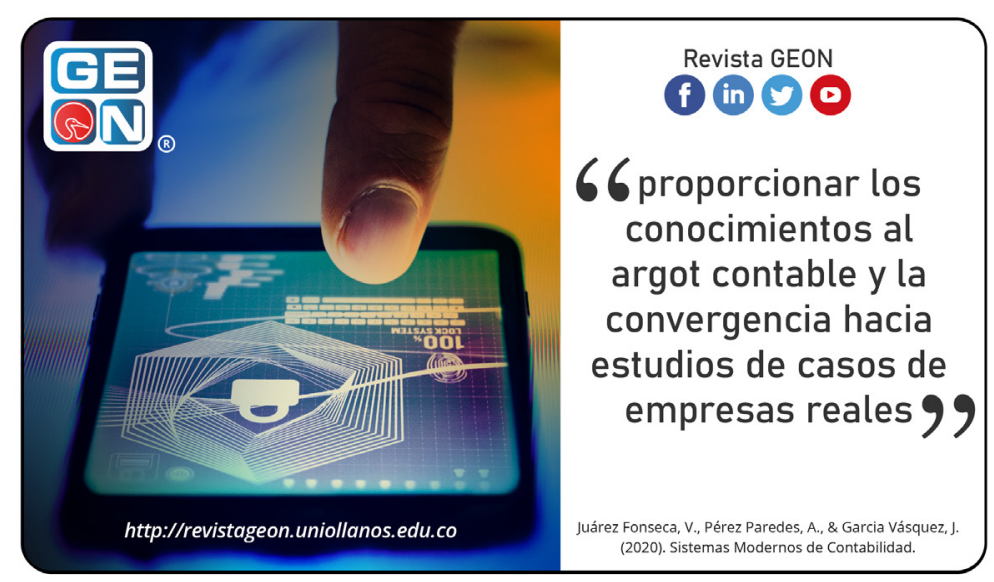

el libro separa la sistematización, de la practicidad hasta llegar a los resultados empresariales para la toma de decisiones de los futuros y actuales contadores de aquella época, a través estados financieros hasta hoy vigentes. Este legado permanece vigente a reserva de los cambios tecnológicos globales.

Palabras clave: Sistemas contables, métodos, contabilidad, estados financieros

\section{Abstract}

The book deals with relevant and current issues about accounting systems, methods and records from the second decade of the 20th century. The first knowledge related to the accounting function is reflected in the univocal contribution that the author consumes with the expression to Castilian, with a particular eloquent and subtle style, without departing from scientific technicalities from another continent. This is the first accounting book in Mexico, which translates concepts and technicalities from English (England and the United States of North America) to Spanish without neglecting Mexican business functions and needs.

Cómo citar este artículo / Toreference this article:

Juárez Fonseca, V., Pérez Paredes, A., \& Garcia Vásquez, J. (2020). Sistemas Modernos de Contabilidad. Revista GEON (Gestión, Organizaciones Y Negocios), 7(2). https://doi. org/10.22579/23463910.220
This first contribution focuses its objective on providing knowledge to accounting slang and convergence towards case studies of real companies that started operations in Mexico, as an attempt to compensate the economy weakened by the after- 
Cómo citar este artículo / Toreference this article:

Juárez Fonseca, V., Pérez Paredes, A., \& Garcia Vásquez, J. (2020). Sistemas Modernos de Contabilidad. Revista GEON (Gestión, Organizaciones Y Negocios), 7(2). https://doi. org/10.22579/23463910.220 math of the Mexican revolution. Likewise, the book separates systematization from practicality until it reaches business results for decision-making by future and current accountants of that time, through financial statements that are still in force today. This legacy remains in force subject to global technological changes.

Keywords: Accounting systems, accounting methods, financial statements

\section{Acerca del autor:}

De elegante vestidura, gallarda presencia y con el ímpetu de contribuir innovaciones financieras y contables a las biosferas empresariales de los años veinte en México, Fernando Diez Barroso dejó un legado para la contaduría a través de su obra bibliográfica denominada "Sistemas modernos de contabilidad"

Considerada como la primera aportación contable para el continente de habla hispana, escrita en escenarios prometedores en el terreno fértil empresarial de México.

Diez Barroso, considerado el primer contador público en México en 1907, fue auditor y contador público titulado (CPT), así como profesor de contabilidad superior y cálculos financieros de la Escuela Superior de Comercio y Administración. Esté fue editado por la Sociedad de Edición y Librería Franco Americana (ELFA).

La segunda edición (1927, la primera en 1926) de la cual se presenta la re- seña siguiente, derivó de la gran demanda que alcanzó en aquella época.

Con la intención de Diez, en proporcionar y facilitar su obra de uso exclusivo para la misma escuela, alcanzó los espacios de aquellos contadores que se incursionaban al ámbito académico y a su misma practicidad profesional.

\section{Introducción.}

El interés que nos ocupa por escribir la presente reseña, motivó desde luego el recién aniversario del contador público, fecha designada al primer titulado (CPT) en México, Fernando Diez Barroso (25 de mayo de 1907). El otro interés que nos animó, fue la impresión significativa que alude al primer libro contable mexicano, escrito por el mismo pionero de la profesión, titulado "Sistemas Modernos de Contabilidad". Aunque la primera edición ocurrió en 1924, la fuerte demanda que este alcanzó, devino en una segunda edición en el año de 1927. Tal escrito no había sido considerado para reseña, por lo que nos centraremos en una exploración sucinta pero significativa. 
En tanto, en este libro se aprecia la atención hacia nuevos proyectos de registros altamente sistematizados, así como innovaciones en el tintero financiero, con la intención de favorecer a la pléyade de la formación profesional del contador público.

La obra impresa de 1927, justifica la valiosa aparición que editó la Sociedad de Edición y Librería Franco Americana, S. A. (ELFA), el uso preferente para estudiantes de la Escuela Superior de Comercio y Administración. (Hoy facultad de Contaduría y Administración de la UNAM). Ese acceso fundamental, permitió que la comunidad universitaria valorara la importancia del manuscrito, atendiendo a las necesidades del asentamiento de nuevas empresas en México. Considerada por sus editores como la primera obra en su género, ofrece a manera de parangón una escritura de expresión al castellano...clara y con atisbo equiparable a los impresos escritos en lengua inglesa de los cuales sólo se podía acceder en el extranjero.

La obra está conformada por dos partes, en la primera se muestran los procesos sistematizados de los registros contables innovadores de aquella época para las recién empresas establecidas en México durante la segunda década del siglo XX. La segunda parte, ofrece estudios de casos reales, para ser puestos en práctica por los estudiosos de la contaduría de aquella época.

La peculiar reseña ofrece al lector un interés histórico y valorativo del papel contador actual del contador como consideración de una base sólida a la edificación de la profesión del contador actual. Se ofrece por tanto, una panorámica del origen de los hoy sistemas modernos de contabilidad... actuales, originados en 1927. No se soslaya, la elocuencia de la escritura que el autor matiza en su libro como reflejo de la gran personalidad atribuible y que observaba.

\section{Sistemas Modernos de Contabilidad}

(Primera parte)

La imperiosa necesidad de ofrecer esta obra de habla hispana en el creciente y desarrollo contexto empresarial de los años veinte, surge los Sistemas Modernos de Contabilidad. La segunda edición, ofreció a los estudiantes e interesados en la contaduría una estructura dividida en dos partes; la primera, se encuentra dividida en doce capítulos, novedosos para aquella época en la que se ofrecieron registros contables paralelos a las transacciones empresariales.

En este apartado del libro Diez, expresa traducciones claras referentes a la sistematización de procesos de orden contable que mostraba por primera vez al futuro contador conceptos hasta hoy perpetuos, per sé, póliza (vouchers), volantes (slips) y centralizador, útiles en la práctica empresarial. Se le atribuye además a este libro, un parte aguas a la herramientas de control interno para la empresas comerciales y financieras; es decir, registros denominados "de diario, mayor único, sistemas de control de cuentas por cobrar y cuentas por pagar". 
Como resultado de estos, Diez ofrece métodos de registro contable como contabilidad analítica, contabilidad sintética, seguido de los sistemas combinados al crecimiento y desarrollo de la hoy fortalecida profesión del contador público en México.

Asimismo, el acápite primero, mostraba elementos conceptuales con ciertos enfoques teóricos para hacerlo más claro. Esta novedad contable presentó por vez primera, nuevos métodos pertinentes aplicables para cada empresa por sus propias características, por lo tanto el orden sistemático atendió a subdivisiones para el registro contable como:

Sistema de diario y caja de partida doble

Sistema de diario tabulador

Sistema de pólizas

Sistema centralizador

Sistemas combinados

Sistema de volantes

Estos registros beneficiaban tanto en tiempo como en procesos, al conocimiento del futuro contador. Los casos presentados a manera de ejemplo como supuestos, fueron perennes a las transacciones comerciales de aquella época, y no estaban ajenos por ningún momento a la realidad que acontecía en el ámbito empresarial, por lo que se ve plasmada la práctica actualizada del autor. Asimismo, muestra un hito prescrito con la legislación mercantil en turno. Por tanto, la pugna entre los registros contables, la práctica (real) y la normatividad, era lo que diez Barroso, innovó como "sis- temas modernos". Esta apología mostró en todo momento ser inexorable de los principios contables, así como la teoría de la partida doble...legado del continente europeo.

\section{De los métodos de registro contable...a la información financiera}

(Segunda parte)

Derivado de los conceptos y de los procesos de registro contable basados en métodos, provenientes del registro de pólizas. La segunda parte del libro, aporta para la historia la conformación de la estructura de estados financieros como por ejemplo, el balance general a nombre de sociedades mercantiles que reflejaban las transacciones comerciales de ejercicios inmediatos anteriores (1926). Por lo que se abordan temas nunca antes explorados, dando paso a estudios financieros para la formación profesional. En tanto crecía el conocimiento en el argot contable, se le sumaban a este apartado, la identificación de "formas contables" denominados como libros de caja; libros de mayor; diario tabular; registros de pólizas de ingreso y egreso; registros de cuentas por cobrar y por pagar. Sin duda, una base secular a los sistemas de información actuales que permean en "programas novedosos".

El libro presenta registros contables elegidos por el autor como resultado de la práctica equiparable a los acontecimientos ocurridos en las empresas; partiendo de casos exitosos que confluyeron en el fortalecimiento para la toma de decisiones de los 
futuros contadores en México. Diez deja a la luz de la pléyade contable que el trabajo del futuro contador ya no sólo debe existir en el escritorio de una oficina, sino que refuerza la participación activa del contador para tener una visión más amplia al fortalecimiento y desarrollo de la profesión, por lo que, además de la toma de decisiones, instó al involucramiento hacia los procesos de una formación profesional holística (diversas especialidades).

Diez subraya la sistematización ordenada y controlada de los registros contables y en consecuencia ampliaba la demanda de estudiosos de la contaduría, por lo que insiste en la necesidad de un "sistema Moderno de contabilidad"... legado imprescindible y perpetuo.

\section{Conclusión}

Consideramos que, a propósito del aniversario de la profesión del contador público en México, la exploración sucinta del primer libro de contabilidad mexicano escrita por el pionero contador público titulado Fernando Diez Barroso, representó dos directrices, una con los novedosos métodos y sistematizaciones contables traducidos al castellano a partir de la segunda década del siglo XX, con la intención de atender a las necesidades de un contexto fértil en el empresarial (ápice de la industria, comercio e instituciones bancarias), lo que permitió sentar las bases para los futuros contadores.

Los métodos y registros contables reflejados en el libro Sistemas Modernos de Contabilidad, presenta estudios de caso de empresas reales que iniciaban una nueva etapa de desarrollo y crecimiento comercial e industrial. En explicaciones detalladas de rubros como caja; cuentas por cobrar; cuentas por pagar; así como registros de pólizas con estructuras claras ad hoc al tipo de entidad, fueron a la luz por primera vez términos y procedimientos una herencia que hoy está vigente. A pesar de que el término "sistemas modernos...", actualmente se traduce en programas tecnológicos innovadores. Aludimos entonces que la modernidad refiriere de los sistemas financieros y contables a necesidades globales económicas, conservando su base procedimental y conceptual de principios del siglo XX.

A diferencia de los libros actuales que atienden a los contextos internacionales, éste en particular advirtió por primera vez, respuestas a interrogantes de registros contables que llevaban más tiempo para su aplicación, o bien, no se tenía acceso a estos, dado que los únicos escritos de formación del contador, se encontraban en el extranjero. La intención clara del contador Diez, era favorecer al estudiantado de aquella época

El escrito fecundo del contador Diez. Sin duda sembró la semilla para la creación de otros escritos contables. En tanto, el libro "Sistemas Modernos de Contabilidad", es un acervo bibliográfico e iconográfico que conquisto a la pléyade de los contadores y profesores del siglo XX y fue el preludio de un lago camino para la formación profesional del contador público en México. 


\section{Referencia.}

Diez B. Fernando. (1927). Sistemas Modernos de Contabilidad. Ed. Sociedad de Edición y Librería Franco Americana, S.A. 